\title{
The burden of the most common rheumatic disease in Colombia
}

\author{
Francy-Milena Cuervo ${ }^{1}$, Ana M. Santos ${ }^{1}$, John Londono ${ }^{1 *}$, José-Ignacio Angarita', Juan C. Rueda ${ }^{1}$, \\ Rodrigo Giraldo-Bustos ${ }^{1}$, Jesús Giovanny Ballesteros-Muñoz' ${ }^{1}$ Eugenia-Lucia Saldarriaga', Diana Padilla-Ortiz ${ }^{1}$, \\ Viviana Reyes-Martinez', Ingris Peláez-Ballestas², Diana Diaz-Jiménez ${ }^{3}$, Pedro Santos-Moreno ${ }^{4}$, \\ Carlos E. Pinzón ${ }^{5}$ and Carlos Castañeda-Orjuela ${ }^{3}$
}

\begin{abstract}
Background: Estimating the burden of rheumatic diseases (RDs) requires proper evaluation of its lethal and nonlethal consequences. In Colombia, it is possible to find local data and Global Burden of Disease (GBD) reports that collect information from varied contexts and apply complex statistical models, but no on-site estimations are available.

Methods: This was a descriptive study on the burden of RD based on occurrence and mortality data in the general population during 2015, including information and prevalence estimations from the Community Oriented Program for the Control of Rheumatic Diseases (COPCORD) study. Disability-adjusted life years (DALYs) were estimated by combining measures of years of life lost (YLL) and years lived with disability (YLDs). For disability weight estimations among cases, different COPCORD responses were mapped using flowcharts to show the severity distribution according to GBD. All model parameters and results were validated through an expert consensus panel.

Results: Low back pain (LBP) was the RD with the greatest burden of disease, costing 606.05 ( $95 \%$ Cl 502.76-716.58) DALYs per 100,000 inhabitants, followed by osteoarthritis $(292.11 ; 95 \% \mathrm{Cl} 205.76-386.85)$ and rheumatoid arthritis (192.46, 95\% Cl 109.7-239.69).

Conclusions: The burden of RD is as high in Colombia as in other countries of the region. The results offer an interesting tool for optimizing healthcare system design as well as for planning the distribution of human and economic resources to achieve early diagnosis and adequate care of these diseases.
\end{abstract}

Keywords: Burden of disease, Rheumatoid arthritis, Low back pain, Osteoarthritis, Colombia

\section{Background}

Rheumatic diseases (RDs) are non-fatal chronic conditions that characteristically present with pain and physical limitations as well as overall functional dependence. They constitute an increasing problem that should not be underestimated [1]. Up to $50 \%$ of people with inflammatory diseases such as rheumatoid arthritis (RA) may

\footnotetext{
*Correspondence: johnlp@unisabana.edu.co

${ }^{1}$ Grupo de Investigación Espondiloartropatías, Universidad de La Sabana

- Hospital Militar Central, Bogotá, Colombia

Full list of author information is available at the end of the article
}

develop permanent disability as a result within 4.5 to 22 years of the diagnosis [2]. Burden of disease (BoD) studies estimate the consequences of having a disease by measuring morbidity and mortality in the population [3]. Previous studies have shown that the burden of RD has been increasing globally since 2010 [4], and the same trend is anticipated to continue as the life expectancy of the population increases.

In 2019, the Global Burden of Disease (GBD) studies reported estimates identifying the most common conditions for varied regions of the world, including some RDs [5]. The researchers applied a robust methodological 
approach imputing missing information with metaregression analyses. For example, in Colombia, they extrapolated data from regions that share common circumstances [5] to measure disability-adjusted life years (DALYs) [6]. Additionally, regional BoD studies have been carried out in Colombia with estimates of RD. The first study was conducted in 2005 and used the prevalence of $\mathrm{RD}$ in the Afro-Colombian population [7]. The second study took place in 2010 and extrapolated the prevalence of RD from Brazilian data [8]. There have been other attempts to assess the burden of RA using national data collected in 2005 [9], but none of them include data representative of the full population.

The Community Oriented Program for the Control of Rheumatic Diseases (COPCORD) strategy [10] was applied to assess the prevalence of RD in Colombia with a population sampling strategy [11]. That study included standardized questionnaires that evaluated quality of life, mechanical load and patient functionality. The most prevalent RD was non-specific musculoskeletal complaints (prevalence in $16.09 \%$ of patients aged 18 or older), followed by osteoarthritis (OA) (10.81\%), appendicular regional pain syndrome $(9.73 \%)$, mechanical low back pain (LBP) (7.24\%), and RA (1.49\%) [11]. The present study uses these newly available data on the prevalence of RD in addition to data found in secondary sources to estimate the burden of RD in DALYs for the Colombian population.

\section{Methods}

\section{Study design}

This is a descriptive analysis of the burden of $\mathrm{RD}$ in DALYs in the Colombian population using secondary information about the prevalence and mortality of LBP, $\mathrm{OA}$ and AR. A multiplicative model considering cases and deaths on the national scale was implemented to compute DALYs due to RD in Colombia. The parameters, model structure and estimations were validated by a panel of clinical experts.

\section{Subjects}

The total number of cases included for each disease was taken from the study "Prevalence of rheumatic disease in Colombia, according to the COPCORD_Colombian Rheumatology Association strategy" [11]. This study used a validated questionnaire [12] and a primary care physician's evaluation with an initial diagnosis; finally, experienced rheumatologists confirmed the initial diagnosis. Microdata from this populational survey were also input for the severity distribution. Causes of death were collected from death certificates, and it was noted if RD was identified as the basic cause of death.

\section{Inclusion criteria}

Participants above the age of 18 years who met the American College of Rheumatology/European League Against Rheumatism (ACR/EULAR) criteria for RA [13], knee [14] or hip [15] OA were included in our secondary analysis.

\section{Exclusion criteria}

All patients with inflammatory LBP who met the European Spondyloarthropathy Study Group (ESSG) criteria [16] or presented with any other LBP-associated diagnosis were excluded [17], according to GBD classification [6].

\section{Model parameters \\ Reference population}

Data about the general population during 2015 were obtained through the National Statistics Administrative Department of Statistics (DANE; Departamento Administrativo Nacional de Estadística) and disaggregated by age and gender.

\section{Prevalence and mortality of RDs}

$\mathrm{RD}$ prevalence was obtained from the result of the COPCORD Colombia study, which included aggregate data for the population aged 18 years or older in six different Colombian cities during 2015, as well as disaggregated RD prevalence estimates by age and gender [11]. Data on mortality were obtained through DANE for each age group and sex for each RD during 2015. Diagnoses were defined using the International Classification of Diseases and Related Health Problems, tenth revision (ICD-10), for RD [6] (Table 1). Those involving cancer, trauma, infection, vascular disorders and inflammatory processes were excluded. Mortality rates according to sex were estimated. To estimate years of life lost (YLL), reference life table data (Additional file 1: Table S1) were obtained from the GBD 2019 study carried out by the Institute for Health Metrics and Evaluation (IHME) [5].

\section{Disease severity}

To identify the associated disability weight (DW) and years lived with disability (YLD), disease severity was categorized as defined in the GBD study [6] (Table 2). For RD patient distribution percentages, the crosswalking method was applied from microdata of the Colombian COPCORD study. This method reclassifies the RD severity by collecting specific questions from the Health Assessment Questionnaire (HAQ) $[18,19]$ and the EuroQol 5-dimensional quality of life scale (EQ-5D) [20, 21] (Additional file 2: Table S2, Additional 
Table 1 Musculoskeletal disorders, equivalent ICD-10 codes and list of sequelae for each disorder in the GBD study

\begin{tabular}{lll}
\hline Disorder & ICD-10 CODES & Sequelae associated \\
\hline Low back pain & M471, M478, M479, M480, M488, M489, M541, M544, M545 & $\begin{array}{l}\text { Mild, moderate, severe and } \\
\text { most severe, without leg } \\
\text { pain } \\
\text { Mild, moderate, severe and } \\
\text { most severe, with leg pain }\end{array}$ \\
$\begin{array}{ll}\text { Osteoarthritis of the knee and hip } \\
\text { Rheumatoid arthritis }\end{array}$ & $\begin{array}{l}\text { Mild, moderate and severe } \\
\text { M05-M06 }\end{array}$ & Mild, moderate and severe
\end{tabular}

ICD-10 International Statistical Classification of Diseases and Related Health Problems, tenth revision

Table 2 GBD 2020 sequelae, health state lay descriptions, and disability weights

\begin{tabular}{|c|c|c|c|}
\hline Diseases & Sequelae & Health state lay description & Disability weight \\
\hline \multirow[t]{8}{*}{ Low back pain } & Mild without leg pain & $\begin{array}{l}\text { The person has mild back pain, which causes some difficulty } \\
\text { dressing, standing, and lifting things }\end{array}$ & $\begin{array}{l}0.02 \\
(0.011-0.035)\end{array}$ \\
\hline & Moderate without leg pain & $\begin{array}{l}\text { The person has moderate back pain, which causes difficulty } \\
\text { dressing, sitting, standing, walking, and lifting things }\end{array}$ & $\begin{array}{l}0.054 \\
(0.035-0.079)\end{array}$ \\
\hline & Severe without leg pain & $\begin{array}{l}\text { The person has severe back pain, which causes difficulty dress- } \\
\text { ing, sitting, standing, walking, and lifting things. The person } \\
\text { sleeps poorly and feels worried }\end{array}$ & $\begin{array}{l}0.272 \\
(0.182-0.373)\end{array}$ \\
\hline & Most severe without leg pain & $\begin{array}{l}\text { The person has constant back pain, which causes difficulty } \\
\text { dressing, sitting, standing, walking, and lifting things. The person } \\
\text { sleeps poorly, is worried, and has lost some enjoyment in life }\end{array}$ & $\begin{array}{l}0.372 \\
(0.25-0.506)\end{array}$ \\
\hline & Mild with leg pain & $\begin{array}{l}\text { The person has mild back pain, which causes some difficulty } \\
\text { dressing, standing, and lifting things }\end{array}$ & $\begin{array}{l}0.02 \\
(0.011-0.035)\end{array}$ \\
\hline & Moderate with leg pain & $\begin{array}{l}\text { The person has moderate back pain, which causes difficulty } \\
\text { dressing, sitting, standing, walking, and lifting things }\end{array}$ & $\begin{array}{l}0,054 \\
(0.035-0.079)\end{array}$ \\
\hline & Severe with leg pain & $\begin{array}{l}\text { The person has severe back and leg pain, which causes difficulty } \\
\text { dressing, sitting, standing, walking, and lifting things. The person } \\
\text { sleeps poorly and feels worried }\end{array}$ & $\begin{array}{l}0.325 \\
(0.219-0.446)\end{array}$ \\
\hline & Most severe with leg pain & $\begin{array}{l}\text { has constant back and leg pain, which causes difficulty The } \\
\text { person dressing, sitting, standing, walking, and lifting things. The } \\
\text { person sleeps poorly, is worried, and has lost some enjoyment } \\
\text { in life }\end{array}$ & $\begin{array}{l}0.384 \\
(0.256-0.518)\end{array}$ \\
\hline \multirow[t]{3}{*}{ Osteoarthritis of the knee and hip } & Mild & $\begin{array}{l}\text { The person has pain in the leg, which causes some difficulty } \\
\text { running, walking long distances, and getting up and down }\end{array}$ & $\begin{array}{l}0.023 \\
(0.013-0.037)\end{array}$ \\
\hline & Moderate & $\begin{array}{l}\text { The person has moderate pain in the leg, which makes the } \\
\text { person limp, and causes some difficulty walking, standing, lifting } \\
\text { and carrying heavy things, getting up and down and sleeping }\end{array}$ & $\begin{array}{l}0.079 \\
(0.054-0.11)\end{array}$ \\
\hline & Severe & $\begin{array}{l}\text { The person has severe pain in the leg, which makes the person } \\
\text { limp and causes a lot of difficulty walking, standing, lifting and } \\
\text { carrying heavy things, getting up and down, and sleeping }\end{array}$ & $\begin{array}{l}0.165 \\
(0.112-0.232)\end{array}$ \\
\hline \multirow[t]{3}{*}{ Rheumatoid arthritis } & Mild & $\begin{array}{l}\text { The person has moderate pain and stiffness in the arms and } \\
\text { hands, which causes difficulty lifting, carrying, and holding } \\
\text { things, and trouble sleeping because of the pain }\end{array}$ & $\begin{array}{l}0.117 \\
(0.08-0.163)\end{array}$ \\
\hline & Moderate & $\begin{array}{l}\text { The person has pain and deformity in most joints, causing } \\
\text { difficulty moving around, getting up and down, and using the } \\
\text { hands for lifting and carrying. The person often feels fatigue }\end{array}$ & $\begin{array}{l}0.317 \\
(0.216-0.44)\end{array}$ \\
\hline & Severe & $\begin{array}{l}\text { The person has severe, constant pain and deformity in most } \\
\text { joints, causing difficulty moving around, getting up and down, } \\
\text { eating, dressing, lifting, carrying and using the hands. The per- } \\
\text { son often feels sadness, anxiety and extreme fatigue }\end{array}$ & $\begin{array}{l}0.581 \\
(0.403-0.739)\end{array}$ \\
\hline
\end{tabular}


file 3: Table S3 and Additional file 4: Table S4). RD severity was calculated for all patients with RA, LBP, or OA. Disability weight values for the estimation of YLD were obtained from GBD 2019 [5] (Table 2).

\section{Burden of disease estimation}

A model describing the prevalence, mortality and disability of RD was built based on Colombian epidemiological data (Table 3). The number of DALYs was estimated as the sum of YLL and YLD. YLL was determined from the age of death and reference life table. To estimate YLDs,

Table 3 Prevalence, mortality and disability of rheumatic disease in Colombia, 2015

\begin{tabular}{|c|c|c|c|c|c|c|}
\hline $\begin{array}{l}\text { Colombian population, } \\
2015^{\infty}\end{array}$ & Male & Female & & & & \\
\hline $18-29$ years & $5,092,439$ & $4,899,545$ & & & & \\
\hline 30-39 years & $3,293,728$ & $3,451,975$ & & & & \\
\hline 40-49 years & $2,760,734$ & $3,002,471$ & & & & \\
\hline $50-59$ years & $2,322,517$ & $2,576,764$ & & & & \\
\hline $60-69$ years & $1,422,161$ & $1,613,617$ & & & & \\
\hline 70-79 years & 719,504 & 891,955 & & & & \\
\hline $80+$ years & 284,046 & 405,568 & & & & \\
\hline \multirow[t]{2}{*}{ Prevalence $(\%)^{*}$} & \multicolumn{2}{|c|}{ Low back pain } & \multicolumn{2}{|c|}{ Osteoarthritis } & \multicolumn{2}{|c|}{ Rheumatoid arthritis } \\
\hline & Male & Female & Male & Female & Male & Female \\
\hline $18-29$ & $\begin{array}{l}4.9 \\
(4.8-4.9)\end{array}$ & $\begin{array}{l}8.9 \\
(8.8-8.9)\end{array}$ & $\begin{array}{l}1.9 \\
(0.7-5.4)\end{array}$ & $\begin{array}{l}2.2 \\
(1.0-4.5)\end{array}$ & 0.0 & $\begin{array}{l}0.5 \\
(0.1-2.2)\end{array}$ \\
\hline $30-39$ & $\begin{array}{l}9.7 \\
(9.6-9.7)\end{array}$ & $\begin{array}{l}7.5 \\
(7.4-7.5)\end{array}$ & $\begin{array}{l}0.9 \\
(0.2-4.2)\end{array}$ & $\begin{array}{l}4.0 \\
(2.2-7.1)\end{array}$ & $\begin{array}{l}0.7 \\
(0.1-4.7)\end{array}$ & $\begin{array}{l}1.1 \\
(0.3-3.3)\end{array}$ \\
\hline $40-49$ & $\begin{array}{l}7.7 \\
(7.6-7.7)\end{array}$ & $\begin{array}{l}7.4 \\
(7.4-7.5)\end{array}$ & $\begin{array}{l}10.1 \\
(3.9-23.7)\end{array}$ & $\begin{array}{l}12.9 \\
(9.7-17)\end{array}$ & 0.0 & $\begin{array}{l}5.3 \\
(3.2-8.7)\end{array}$ \\
\hline $50-59$ & $\begin{array}{l}9.9 \\
(9.8-9.9)\end{array}$ & $\begin{array}{l}6.7 \\
(6.6-6.7)\end{array}$ & $\begin{array}{l}11.9 \\
(7.8-17.9)\end{array}$ & $\begin{array}{l}23.1 \\
(19.3-27.4)\end{array}$ & $\begin{array}{l}1.4 \\
(0.4-4.8)\end{array}$ & $\begin{array}{l}3.2 \\
(1.8-5.5)\end{array}$ \\
\hline $60-69$ & $\begin{array}{l}5.5 \\
(5.5-5.6)\end{array}$ & $\begin{array}{l}5.9 \\
(5.9-6.0)\end{array}$ & $\begin{array}{l}13.2 \\
(9.1-18.7)\end{array}$ & $\begin{array}{l}29.4 \\
(24.5-34.8)\end{array}$ & 0.0 & $\begin{array}{l}2.3 \\
(1.1-4.8)\end{array}$ \\
\hline $70-79$ & $\begin{array}{l}8.1 \\
(7.9-8.3)\end{array}$ & $\begin{array}{l}4.6 \\
(4.5-4.7)\end{array}$ & $\begin{array}{l}27.9 \\
(20.7-36.5)\end{array}$ & $\begin{array}{l}38.2 \\
(31.9-44.9)\end{array}$ & $\begin{array}{l}1.6 \\
(0.4-6.4)\end{array}$ & $\begin{array}{l}3.4 \\
(1.6-7.3)\end{array}$ \\
\hline $80+$ & $\begin{array}{l}4.7 \\
(4.6-4.8)\end{array}$ & $\begin{array}{l}1.9 \\
(1.9-2.0)\end{array}$ & $\begin{array}{l}27.1 \\
(14.8-44.3)\end{array}$ & $\begin{array}{l}35.6 \\
(25.7-46.9)\end{array}$ & 0.0 & $\begin{array}{l}3.1 \\
(0.8-11.7)\end{array}$ \\
\hline $\begin{array}{l}\text { Mortality by age group } \\
(n)^{\infty}\end{array}$ & Male & Female & Male & Female & Male & Female \\
\hline $18-29$ years & 0 & 0 & 0 & 0 & 0 & 0 \\
\hline 30-39 years & 0 & 0 & 0 & 0 & 0 & 0 \\
\hline 40-49 years & 0 & 0 & 0 & 0 & 0 & 0 \\
\hline $50-59$ years & 0 & 0 & 0 & 0 & 0 & 0 \\
\hline $60-69$ years & 3 & 0 & 3 & 2 & 0 & 0 \\
\hline $70-79$ years & 0 & 2 & 9 & 13 & 0 & 0 \\
\hline $80+$ years & 3 & 1 & 12 & 47 & 0 & 0 \\
\hline \multicolumn{7}{|l|}{ Disability $(\%)^{*}$} \\
\hline Mild & 44 & & 63 & & 55 & \\
\hline Moderate & 28 & & 28 & & 33 & \\
\hline Severe & 17 & & 9 & & 12 & \\
\hline Most severe & 11 & & & & & \\
\hline
\end{tabular}

*Prevalence calculated for patients aged 18 years or older. Londoño J, Peláez-Ballestas I, Cuervo F, Angarita I, Giraldo R, Rueda JC, et al. Prevalencia de la enfermedad reumática en Colombia, según estrategia COPCORD-Asociación Colombiana de Reumatología. Estudio de prevalencia de enfermedad reumática en población colombiana mayor de 18 años. Revista Colombiana de Reumatología. 2018;25(4):245-56 [11].

$\infty$ Data from National Statistics Administrative Department of Statistics (DANE; Departamento Administrativo Nacional de Estadística)

¥ Cross-walking method (Additional file 2: Table S2, Additional file 3: Table S3 and Additional file 4: Table S4) 
we combined the severity distribution of the included diseases and the corresponding DW values [22].

$$
\mathrm{DALY}=\mathrm{YLL}+\mathrm{YLD}
$$

where

$$
\mathrm{YLL}=\mathrm{N} \times \mathrm{L}
$$

$\mathrm{N}=$ number of deaths, $\mathrm{L}=$ standard life expectancy at age of death in years.

$$
\mathrm{YLD}=\mathrm{P} \times \mathrm{DW}
$$

$\mathrm{P}=$ prevalence in number of cases, $\mathrm{DW}=$ disability weight.

The model was built and programmed using MS Excel $^{\circledR}$, in accordance with transparency and usability criteria for external users, with the possibility of applying it for other RD scenarios.

\section{Sensitivity analysis}

Uncertainty for all model parameters was expressed as 95\% confidence intervals (CIs). A probabilistic sensitivity analysis was performed for each parameter using the Monte Carlo method, which ran 10,000 iterations of the model where each parameter had independent stochastic variation within its range of uncertainty. Finally, central tendency and confidence intervals were calculated for each final estimate by RD and by sex.

\section{Expert panel validation}

Parameters such as the model design, structure and preliminary results of this investigation were identified and validated through expert panel consensus. Clinical and methodological experts were given a questionnaire specifically designed for the study, and afterwards, a meeting following the Delphi method was organized, where consensus between all parts was evaluated [23, 24].

\section{Results}

Number of cases and disease severity Low back pain

An estimated 2,390,256 cases were registered in 2015. Most of them were between the ages of 18 and 29 years, and more women than men were affected (Fig. 1). The severity distribution for low back with leg pain was $58 \%$ mild, $12 \%$ moderate, $12 \%$ severe, and $18 \%$ very severe. For low back without leg pain was $43 \%$ mild, $30 \%$ moderate, $18 \%$ severe, and 10 very severe $\%$.

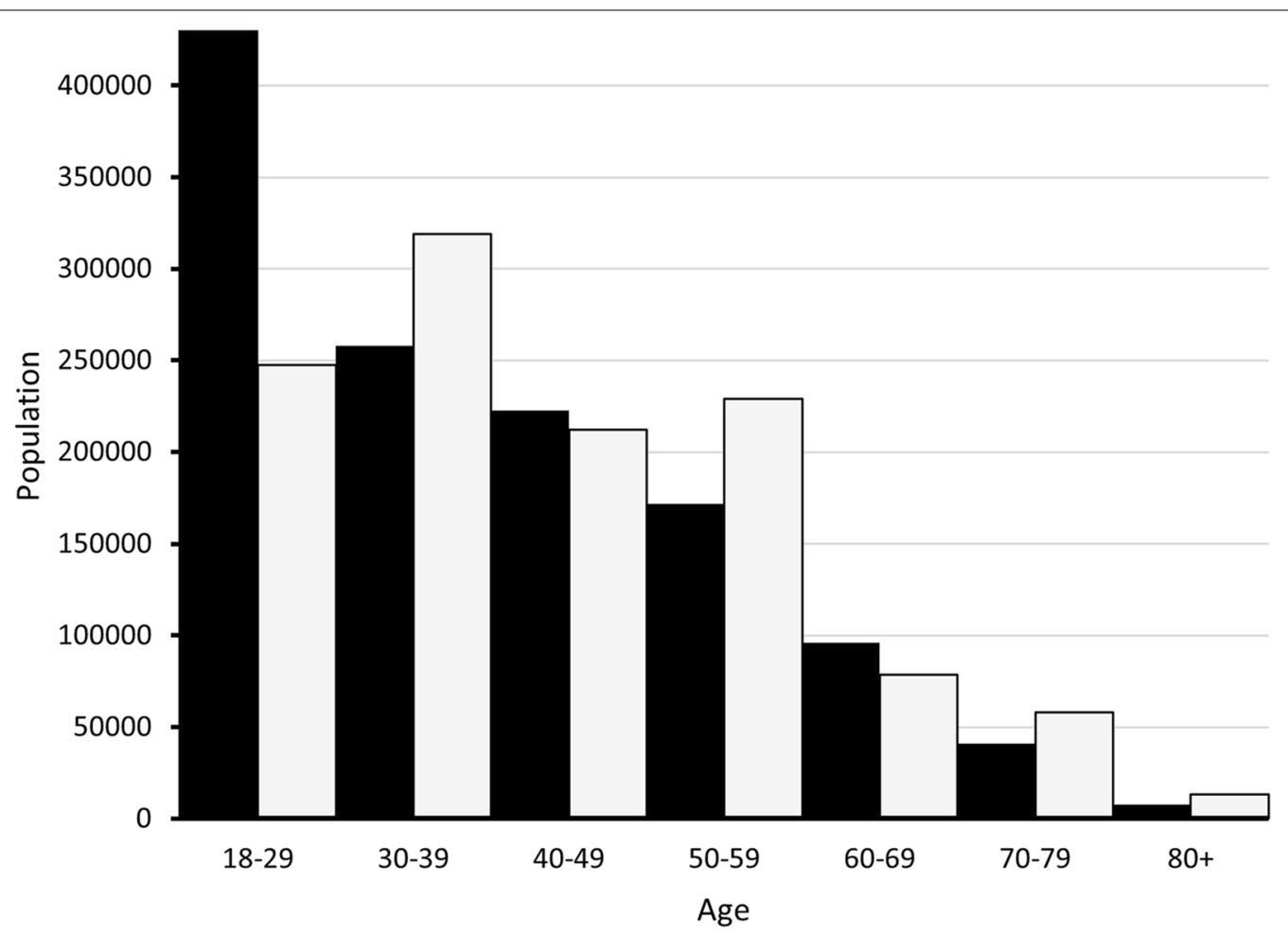

Fig. 1 Age and sex distribution of low back pain cases

- Femal $\square$ Male 


\section{Osteoarthritis}

This was the disease with most cases estimated by the model, with a total of 3,335,553 in 2015. Among them, $63 \%$ were mild, $28 \%$ were moderately severe, and $9 \%$ were very severe. Most patients were between 50 and 59 years of age (Fig. 2).

\section{Rheumatoid arthritis}

An estimated 451,173 cases were reported, mainly females aged between 40 and 60 years (Fig. 3). Regarding severity distribution, $55 \%$ of cases were mild, $33 \%$ were moderate and $12 \%$ were severe.

\section{Mortality}

According to the ICD-10, there were no registered deaths attributable to RA in 2015. DANE was registered as a basic cause of death for 6 men and 3 women with LBP. For OA, 24 male deaths and 62 female deaths were recorded. Regarding the direct causes of death, one-quarter of deaths were related to complications of surgical procedures for spinal stenosis or OA. Approximately $45 \%$ of deaths were due to infections, and $25 \%$ were due to cardiovascular disorders such as pulmonary embolism and cardiovascular disease. In several

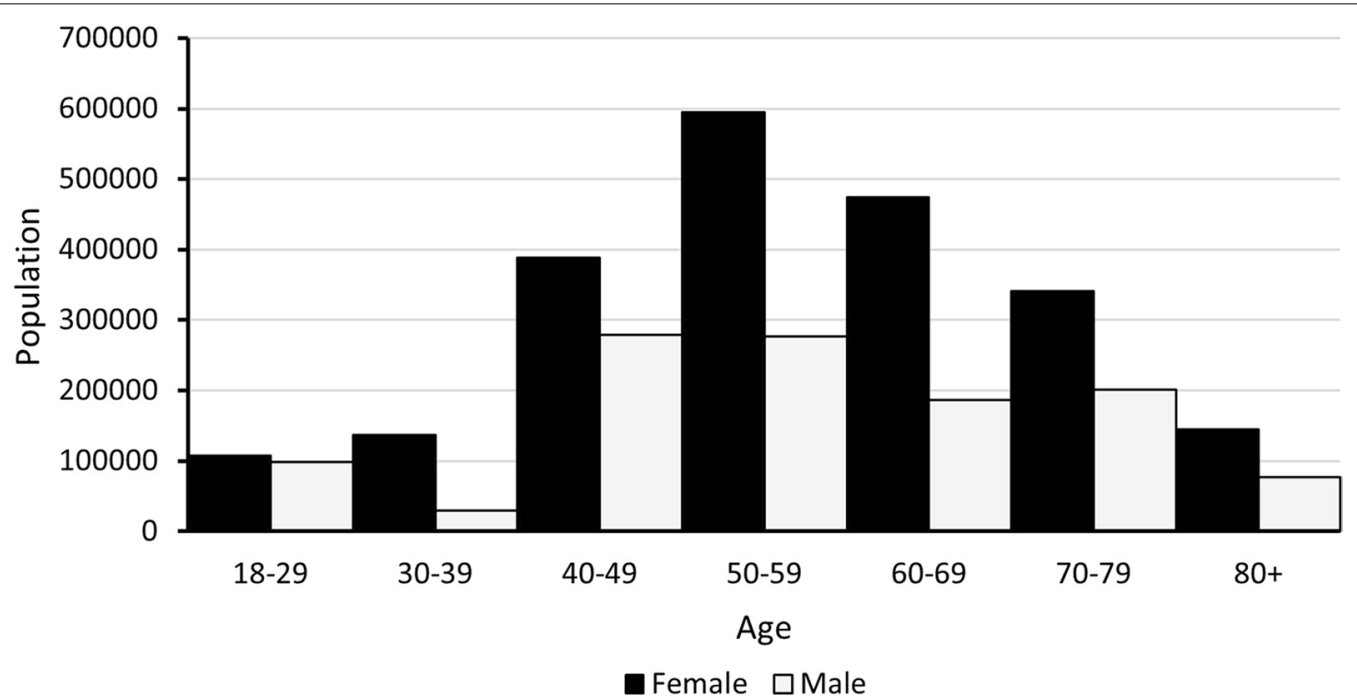

Fig. 2 Age and sex distribution of osteoarthritis cases

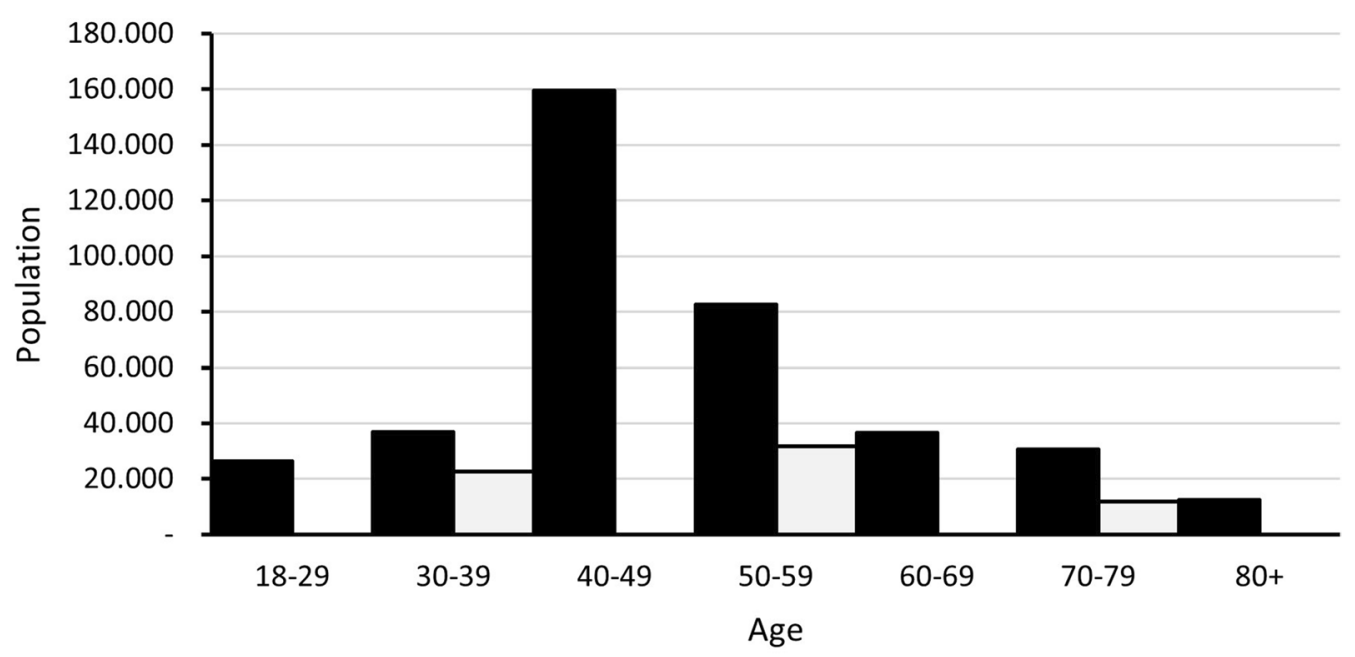

Female $\square$ Male

Fig. 3 Age and sex distribution of rheumatoid arthritis cases 
cases, the direct cause could not be determined, possibly due to an error in the registry.

\section{Burden of rheumatic diseases in Colombia}

The main source of RD burden in Colombia is LBP, followed by OA and RA. Table 4 represents years of healthy life lost for each of them. Table 5 corresponds to the BoD distribution in terms of DALYs per 100,000 population; most of the patients are female.

\section{Burden of disease model validation}

The panel unanimously considered the estimation of total cases for LBP, OA, and RA for 2015 in Colombia to be reliable. As for the severity distribution data, the panel agreed with low back pain and OA findings but suggested RA flowchart redistribution to obtain more accurate results. The methodology and results for DALY calculation were approved. The panel determined that age had a stronger influence on LBP and OA than on RA. Considering the quality of information systems as well as the epidemiological profiles of RD, experts proposed Mexico, Brazil and Peru as adequate comparators of the results.

\section{Discussion}

The present study is the first attempt to establish the burden of RD in Colombia by applying the methods used in GBD study using local data and data obtained through quality of life and functionality questionnaires. The burden of disease (BoD) for low back pain (LBP) was estimated to be 606.05 DALYs per 100,000 population, with a total of 2,390,256 cases. The estimates were 292.11 DALYs per 100,000 population, and a total of $3,335,553$ cases of osteoarthritis (OA). There were 451,173 cases of rheumatoid arthritis (RA), with a DALY of 192.46 per 100,000 .

Values for DALYs correspond mainly to YLD, which can be explained by the fact that the studied conditions tend to cause higher morbidity than mortality. The severity of disease is related to the estimation of YLD (Table 4). Patients who suffer from RDs experience severe limitations even in basic activities of daily living due to pain and fatigue [25].
Table 5 DALY rates per 100,000 population by sex, Colombia, 2015

\begin{tabular}{lll}
\hline & Male & Female \\
\hline Low back pain & $96,051(79,921-113,392)$ & $\begin{array}{c}102,352(84,668- \\
121,194)\end{array}$ \\
Osteoarthritis & $33,062(21,388-46,830)$ & $62,567(45,971-79,812)$ \\
Rheumatoid arthritis & $10,195(1470-22,196)$ & $52,812(34,443-73,949)$ \\
\hline
\end{tabular}

LBP is a heterogeneous disease and a very common cause of outpatient consultations. Most patients require long-term conservative treatments [26]. Up to $25 \%$ of cases exhibit some disability when surgical intervention is required [27]. Overall, 32.4\% of LBP patients present mild disability, $45.9 \%$ moderate, $20.7 \%$ severe, and $0.9 \%$ extreme [28] on the Oswestry Disability Index (ODI) [29]. Nonetheless, our analysis estimates more cases in the severe and extreme categories.

The prevalence of hip and knee OA increases past the age of 55 years, and it is likely to increase further due to the ageing of the population; thus, it is necessary to find cost-effective measures to mitigate long-term disability $[30,31]$ and to manage the resources of the Colombian healthcare system. The Western Ontario and McMaster Universities Osteoarthritis Index (WOMAC) [32], commonly employed to assess symptoms and functionality in patients, permits good radiological and functional correlation, allowing for a precise severity assessment. In one study, [33] the distribution of severity was as follows: $60.7 \%$ mild, $36 \%$ moderate and 3.3\% severe. Similar results were found in this study.

Disease activity entails an increasing degree of disability in the natural course of RA [34]. Therefore, strict evaluation and treatment have a positive impact in reducing sequelae [35]. The disease severity distribution for the present study is similar to that found in other cohorts using the HAQ disability index: $63 \%$ mild, $25.2 \%$ moderate, and $11.8 \%$ severe [36].

The increase in population life expectancy affects the burden of RDs, as the prevalence and disability rates increase with ageing. In any case, it is important to

Table 4 Burden of disease in Colombia: low back pain, osteoarthritis and rheumatoid arthritis. Colombia, 2015

\begin{tabular}{llll}
\hline & Low back pain $(\mathbf{9 5 \%} \mathbf{C l})$ & Osteoarthritis $\mathbf{( 9 5 \% ~ C l )}$ & Rheumatoid arthritis (95\% Cl) \\
\hline YLL $^{*}$ & $62(0-124)$ & $393(96-687)$ & 0 \\
YLD $^{¥}$ & $198,341(164,525-234,517)$ & $95,237(66,937-126,225)$ & $63,007(35,913-96,145)$ \\
DALY & $198,403(164,589-243,586)$ & $95,629(67,359-126,642)$ & $63,007(35,913-96,145)$ \\
DALYs per-100,000 & $606.05(502.76-716.58)$ & $292.11(205.76-386.85)$ & $192.46(109.7-293.69)$
\end{tabular}

*Years of life lost

$¥$ Years lived with disability

${ }^{\infty}$ Disability-adjusted life years 
consider the influence of other factors, such as tobacco use, inactivity, unhealthy diet and obesity, on the appearance of diseases at an early age [37].

\section{Comparison with local BoD estimates}

DALY estimation for LBP corresponds to the GBD 2019 findings [rate of 951.74 DALYs per 100,000 population (95\% CI 664.24-1275.07)]; for OA, the value was similar to that reported by the GBD 2019, with 226.45 DALYs per 100,000 population [95\% CI 113.65-457.42)]. Meanwhile, DALY rates for RA were four times the value observed in the GBD study [51.26 DALYs per 100,000 population (95\% CI 37.64-66.92)] [5].

RD prevalence was a key factor in determining our results because the values for RD prevalence in GBD 2019, 0.4\% (95\% CI 0.36-0.46) for RA, $11.41 \%$ (95\% CI 10.11-12.77) for LBP and 8.73\% (95\% CI 7.84-9.70) for OA [5], were significantly lower than those used for the present study. Local RD prevalence data was sourced from a rigorously designed study [11].

There have been two previous BoD studies in Colombia. One registered burden of OA locally found it to be 380 DALY per 100,000 population in 2005 [7] and found this rate to increase up to 800 DALY per 100,000 population in 2010 for patients aged 70 to 79 , including males and females [8]. In 2005, RA had 232 total DALYs per 100,000 population for women of all ages [7], and women aged 70 to 79 years, with 400 DALYs per 100,000 population, had the greatest value in 2010 [8]. Disability rates were the main contributor to DALY values in the 2005 and 2010 studies as well as in our own. It is worth noting that our results are lower than these values by half, and even though the methodology and data sources were different, we cannot discard the possibility of it being a direct result of treat-to-target strategies implemented locally [38].

When comparing our results to those from GBD 2019 [5] for countries with epidemiological characteristics similar to Colombia, we noted that the DALYs estimated for OA and RA were greater in the present study (Table 6). We suspect that factors such as delayed rheumatology consultation, limited access to second-line therapy, and the economic impact these imply for the healthcare system are potentially related to these findings [39].

\section{Comparison with other diseases}

According to GBD 2019, cardiovascular disease is the main cause of DALY in Colombia [2819.8 DALY per 100,000 population (2257.73-3520.63)]. However, RD a highly prevalent group of diseases compared with other common conditions, such as diabetes [1000.6 (755.69-1282.64) DALY per 100,000 population], chronic obstructive pulmonary disease [596.18 (476.85-726.87) DALY per 100,000 population], chronic kidney disease [546.85 (444.28-671.65) DALY per 100,000], depression (307.03 (210.6-421.91) DALY per 100,000) and human immunodeficiency virus/acquired immunodeficiency syndrome [261.42 (246.72-277.29) DALY per 100,000 population] [5].

\section{Public health implications}

The prevalence of osteoarticular disease is expected to progressively increase [40]. In the United States, a 2013 medical cost analysis found that half of all adult medical expenses were for arthritis patients. National medical costs attributable to arthritis were $\$ 139.8$ billion (between $\$ 135.9$ and $\$ 157.5$ billion). It represents an additional \$2117 per adult with arthritis [41]. Establishing healthcare models and therapies must be prioritized to guarantee timely diagnosis and adequate medical interventions in order to control disease activity and reduce disability progression [35], the activity of the disease is related to more medical costs. In addition, projections for the year 2030 estimate an increasing need for rheumatologists in the USA [42]. In Colombia, as in the United States, there is an uneven distribution of specialists, as they remain centralized in urban, densely populated areas [43]. The present study attempts to assess the current national RD status in an effort to evaluate the short-, medium-, and long-term impact these conditions have on healthcare systems.

It is important to recognize the limitations of this study. The first of these limitations is that the data originated from secondary sources and are therefore subject to possible registration bias. Because of this risk, all

Table 6 Disability-adjusted life years (DALYs) of low back pain, osteoarthritis and rheumatoid arthritis based on the GBD 2019 study

\begin{tabular}{llll}
\hline DALYs per 100,000* & Low back pain & Osteoarthritis & Rheumatoid arthritis \\
\hline Mexico & $738.45(3520.76-985.55)$ & $256.89(131.12-499.99)$ & $81.79(63.01-104.47)$ \\
Peru & $686.55(483.68-923.38)$ & $195.69(98.42-395.25)$ & $38.68(28.09-51.01)$ \\
Brazil & $943.44(665.46-1253.4)$ & $229.64(115.24-454.73)$ & $47.77(34.77-61.59)$ \\
\hline
\end{tabular}

Global burden of 369 diseases and injuries in 204 countries and territories, 1990-2019: a systematic analysis for the Global Burden of Disease Study 2019. Lancet (London, England). 2020;396(10,258):1204-22. [5]. https://vizhub.healthdata.org/gbd-compare/

*DALYs per 100,000 
included data parameters were validated by an expert panel. Second, all prevalence data corresponded to highly populated areas, and no regional disaggregation was performed; instead, a national estimate was used. Another limitation of our study is related to the LBP classification as a rheumatic diseases. However, the classification used in our analysis is the same used by the GBD. These assessed diseases cannot yet be ungrouped, so it is very difficulty to collect good quality data on each topic.

Although it may not correspond to an inflammatory rheumatic disease, its frequency and impact on the functional capacity of affected individuals are very important.

\section{Conclusions}

Rheumatic diseases in Colombia represent an important burden of disease in terms of DALYs. Our results could be considered a starting point for the design and development of public health policies and strategies to help mitigate disability and its effects on quality of life. The study was developed within the GBD framework because it is particularly useful in the analysis of rheumatic diseases and can easily be applied to study other rheumatic diseases not included in this study.

\footnotetext{
Abbreviations

BoD: Burden of disease; GBD: Global Burden of Disease; RD: Rheumatic disease; COPCORD: Community Oriented Program for the Control of Rheumatic Diseases; DALY: Disability-adjusted life years; YLLs: Years of life lost; YLDs: Years lost due to disability; LBP: Low back pain; RA: Rheumatoid arthritis; OA: Osteoarthritis; ACR/EULAR: American College of Rheumatology/European League Against Rheumatism; ESSG: European Spondyloarthropathy Study Group; DANE: Departamento Administrativo Nacional de Estadística; ICD: International Classification of Diseases; IHME: The Institute for Health Metrics and Evaluation; HAQ: Health Assessment Questionnaire; N: Number of deaths: $\mathrm{L}$ : Standard life expectancy at age of death in years; P: Prevalence in number of cases; DW: Disability weight; ODI: Oswestry Disability Index; WOMAC: Western Ontario and McMaster Universities Osteoarthritis Index; EQ-5D: EuroQol fivedimensional questionnaire.
}

\section{Supplementary Information}

The online version contains supplementary material available at https://doi. org/10.1186/s41927-021-00234-y.

Additional file 1. Institute for Health Metrics and Evaluation (IHME) and Global Burden of Disease Study 2016 (GBD 2016), reference life table.

Additional file 2. Cross walking algorithm for rheumatoid arthritis sequelae.

Additional file 3. Cross walking algorithm for low back pain sequelae. Additional file 4. Cross walking algorithm for osteoarthritis sequelae.

\section{Acknowledgements}

We gratefully acknowledge the institutions that contributed within their respective specialty fields: the Colombian National Health Observatory, National Health Institute, for supporting our methodology, and to the Universidad de La Sabana for their academic support. We also thank all expert panellists and the COPCORD Colombia organizing committee for their participation. Finally, we thank the EuroQol Research Foundation in association with the
Universidad de La Sabana, who permitted the use of the EQ-5D-3L instrument for the assessment of patient quality of life.

\section{Authors' contributions}

FMC, JL, CCO, PSM, CEP, IPB, AMS developed the concept and designed the research; FMC, JL, JIA, JCR, RGB, JGBM, ELS, AMS, DPO, VRM acquired the data; FMC, JL, DDJ, CCO, CEP, IPB analysed and interpreted the data; FMC, JL, DDJ, $\mathrm{CCO}$, IPB prepared and revised the manuscript. All authors read and approved the final manuscript.

\section{Funding}

Concerning funding, the Asociación Colombiana de Reumatología (ASOREUMA) contributed to the financial support of this research (Acta No 156, 31 May 2014). No financial support or benefits were received from commercial sources, and no additional conflicts of interest exist regarding this work.

Availability of data and materials

The datasets used and/or analysed during the current study are available from the corresponding author on reasonable request: johnlp@unisabana.edu.co.

\section{Declarations}

\section{Ethics approval and consent to participate}

The study followed the norms established by the Helsinki Declaration, the Guidelines for Good Clinical Practice, and Resolution 8430 (1993) of the Colombian Ministry for Social Protection. Moreover, it was reviewed and approved by the Ethics Committee of the University of La Sabana (Acta 1470/ December 12, 2017). All study participants signed an informed consent document.

\section{Consent for publication}

Not applicable.

\section{Competing interests}

The authors declare that they have no competing interests.

\section{Author details}

${ }^{1}$ Grupo de Investigación Espondiloartropatías, Universidad de La Sabana Hospital Militar Central, Bogotá, Colombia. ${ }^{2}$ Rheumatology Unit, Hospital General de México, México City, Mexico. ${ }^{3}$ National Health Observatory, National Health Institute, Bogotá, Colombia. ${ }^{4}$ BIOMAB IPS, Bogotá, Colombia. ${ }^{5}$ Epidemiology Department, Universidad de La Sabana, Chía, Colombia.

Received: 5 April 2021 Accepted: 21 September 2021

Published online: 20 January 2022

\section{References}

1. Woolf AD, Akesson K. Understanding the burden of musculoskeletal conditions. The burden is huge and not reflected in national health priorities. BMJ (Clinical research ed). 2001;322(7294):1079-80.

2. Burton W, Morrison A, Maclean R, Ruderman E. Systematic review of studies of productivity loss due to rheumatoid arthritis. Occup Med (Oxford, England). 2006;56(1):18-27.

3. Mathers $C D$, Sabaté $E$, Lopez AD. Guidelines for epidemiological reviews: the Global Burden of Disease 2000 project. Global Programme on Evidence for Health Policy World Health Organization. 2001.

4. Hoy DG, Smith E, Cross M, Sanchez-Riera L, Blyth FM, Buchbinder R, et al. Reflecting on the global burden of musculoskeletal conditions: lessons learnt from the global burden of disease 2010 study and the next steps forward. Ann Rheum Dis. 2015;74(1):4-7.

5. Global burden of 369 diseases and injuries in 204 countries and territories, 1990-2019: a systematic analysis for the Global Burden of Disease Study 2019. Lancet (London, England). 2020;396(10258):1204-22.

6. Murray CJ, Ezzati M, Flaxman AD, Lim S, Lozano R, Michaud C, et al. GBD 2010: design, definitions, and metrics. Lancet (London, England). 2012;380(9859):2063-6. 
7. Ramirez NA, Peñaloza R, García J. Carga de enfermedad Colombia 2005: resultados alcanzados. Bogotá: Pontificia Universidad Javeriana; 2008.

8. Peñaloza Quintero RE, Salamanca Belén N, Rodríguez Hernández JM, Rodríguez García J, Beltran Villegas AR. Estimación de la carga de enfermedad para Colombia, 2010. 2014.

9. Díaz-Rojas JA, Dávila-Ramírez FA, Quintana-López G, Aristizábal-Gutiérrez F, Brown P. Prevalencia de artritis reumatoide en Colombia: una aproximación basada en la carga de la enfermedad durante el año 2005. Rev Colombiana de Reumatol. 2016:23(1):11-6.

10. Chopra A. The COPCORD world of musculoskeletal pain and arthritis. Rheumatology (Oxford). 2013;52(11):1925-8.

11. Londoño J, Peláez-Ballestas I, Cuervo F, Angarita I, Giraldo R, Rueda JC, et al. Prevalencia de la enfermedad reumática en Colombia, según estrategia COPCORD-Asociación Colombiana de Reumatología. Estudio de prevalencia de enfermedad reumática en población colombiana mayor de 18 años. Revista Colombiana de Reumatología. 2018;25(4):245-56.

12. Ballestas IP, Santos AM, Angarita I, Rueda JC, Ballesteros JG, Giraldo R, et al. Cross-cultural adaptation of the Community Oriented Program for the Control of Rheumatic Diseases (COPCORD) in a Colombian population. Rev Colombiana de Reumatol (English Edition). 2019;26(2):88-96.

13. Aletaha D, Neogi T, Silman AJ, Funovits J, Felson DT, Bingham CO 3rd, et al. 2010 Rheumatoid arthritis classification criteria: an American College of Rheumatology/European League Against Rheumatism collaborative initiative. Arthritis Rheum. 2010;62(9):2569-81.

14. Altman R, Asch E, Bloch D, Bole G, Borenstein D, Brandt K, et al. Development of criteria for the classification and reporting of osteoarthritis. Classification of osteoarthritis of the knee. Diagnostic and Therapeutic Criteria Committee of the American Rheumatism Association. Arthritis and rheumatism. 1986;29(8):1039-49.

15. Altman R, Alarcon G, Appelrouth D, Bloch D, Borenstein D, Brandt K, et al. The American College of Rheumatology criteria for the classification and reporting of osteoarthritis of the hip. Arthritis Rheum. 1991;34(5):505-14.

16. Dougados M, van der Linden S, Juhlin R, Huitfeldt B, Amor B, Calin A, et al. The European Spondylarthropathy Study Group preliminary criteria for the classification of spondylarthropathy. Arthritis Rheum. 1991;34(10):1218-27.

17. Airaksinen O, Brox J, Cedraschi C, Hildebrandt J, Klaber-Moffett J, Kovacs $\mathrm{F}$, et al. Chapter 4. European guidelines for the management of chronic nonspecific low back pain. Eur Spine J. 2006;15 Suppl 2:S192-300

18. Cardiel MH, Abello-Banfi M, Ruiz-Mercado R, Alarcon-Segovia D. How to measure health status in rheumatoid arthritis in non-English speaking patients: validation of a Spanish version of the Health Assessment Questionnaire Disability Index (Spanish HAQ-DI). Clin Exp Rheumatol. 1993;11(2):117-21.

19. Cuervo F, Santos A, Saldarriaga E, Rueda J, Angarita I, Ballesteros J, et al. AB1299 functional capacity measured by haq in patients with rheumatic diseases in colombia. Ann Rheum Dis. 2018;77:1742.

20. Brooks R. EuroQol: the current state of play. Health Policy (Amsterdam, Netherlands). 1996;37(1):53-72.

21. Cuervo F, Santos A, Rueda J, Angarita I, Saldarriaga E, Giraldo R, et al. AB1244 Quality life in patients with rheumatic disease, non-rheumatic diseases and healthy population. BMJ Publishing Group Ltd; 2018

22. Lopez AD, Mathers CD, Ezzati M, Jamison DT, Murray CJL. Measuring the Global Burden of Disease and Risk Factors, 1990-2001. In: Lopez AD, Mathers CD, Ezzati M, Jamison DT, Murray CJL, editors. Global Burden of Disease and Risk Factors. Washington (DC): World Bank

23. The International Bank for Reconstruction and Development/The World Bank Group.; 2006.

24. Yáñez Gallardo R, Cuadra OR. La técnica Delphi y la investigación en los servicios de salud. Ciencia y enfermería. 2008;14(1):9-15.

25. McGinnis PQ, Wainwright SF, Hack LM, Nixon-Cave K, Michlovitz S. Use of a Delphi panel to establish consensus for recommended uses of selected balance assessment approaches. Physiother Theory Pract. 2010;26(6):358-73.

26. Verbrugge LM, Juarez L. Profile of arthritis disability: II. Arthritis Rheum. 2006;55(1):102-13.

27. Olafsson G, Jonsson E, Fritzell P, Hagg O, Borgstrom F. A health economic lifetime treatment pathway model for low back pain in Sweden. J Med Econ. 2017;20(12):1281-9.
28. Gelalis ID, Stafilas KS, Korompilias AV, Zacharis KC, Beris AE, Xenakis TA. Decompressive surgery for degenerative lumbar spinal stenosis: longterm results. Int Orthop. 2006;30(1):59-63.

29. Payares K, Lugo LH, Morales V, Londono A. Validation in Colombia of the Oswestry disability questionnaire in patients with low back pain. Spine. 2011;36(26):E1730-5.

30. Roland M, Fairbank J. The Roland-Morris Disability Questionnaire and the Oswestry Disability Questionnaire. Spine. 2000;25(24):3115-24.

31. Sharif B, Kopec J, Bansback N, Rahman MM, Flanagan WM, Wong H, et al. Projecting the direct cost burden of osteoarthritis in Canada using a microsimulation model. Osteoarthritis Cartilage. 2015;23(10):1654-63.

32. Losina E, Burbine SA, Suter LG, Hunter DJ, Solomon DH, Daigle ME, et al. Pharmacologic regimens for knee osteoarthritis prevention: can they be cost-effective? Osteoarthritis Cartilage. 2014;22(3):415-30.

33. Bellamy N, Buchanan WW, Goldsmith CH, Campbell J, Stitt LW. Validation study of WOMAC: a health status instrument for measuring clinically important patient relevant outcomes to antirheumatic drug therapy in patients with osteoarthritis of the hip or knee. J Rheumatol. 1988;15(12):1833-40.

34. Gorial FI, Anwer Sabah SA, Kadhim MB, Jamal NB. Functional status in knee osteoarthritis and its relation to demographic and clinical features. Mediterranean J Rheumatol. 2018;29(4):207-10.

35. Kobelt $G$, Lindgren $P$, Lindroth $Y$, Jacobson L, Eberhardt K. Modelling the effect of function and disease activity on costs and quality of life in rheumatoid arthritis. Rheumatology (Oxford). 2005;44(9):1169-75.

36. Santos-Moreno P, Alvis-Zakzuk NJ, Villarreal-Peralta L, CarrasquillaSotomayor M, Paternina-Caicedo A, Alvis-Guzman N. A comprehensive care program achieves high remission rates in rheumatoid arthritis in a middle-income setting. Experience of a Center of Excellence in Colombia. Rheumatol Int. 2018;38(3):499-505.

37. Munoz JGB, Giraldo RB, Santos AM, Bello-Gualteros JM, Rueda JC, Saldarriaga EL, et al. Correlation between rapid-3, DAS28, CDAl and SDAI as a measure of disease activity in a cohort of Colombian patients with rheumatoid arthritis. Clin Rheumatol. 2017;36(5):1143-8.

38. Woolf AD, Erwin J, March L. The need to address the burden of musculoskeletal conditions. Best Pract Res Clin Rheumatol. 2012;26(2):183-224.

39. Machado-Alba JE, Ruiz AF, Morales DAM. The epidemiology of rheumatoid arthritis in a cohort of Colombian patients. Revista Colombiana de Reumatología. 2015;22(3):148-52.

40. Machado-Alba JE, García-Betancur S, Calvo-Torres LF, Medina-Morales DA, Bañol-Giraldo AM. Time to and factors associated with initiation of biological therapy in patients with rheumatoid arthritis in Colombia. Rev Colombiana de Reumatol. 2018;25(1):3-8.

41. Harkness EF, Macfarlane GJ, Silman AJ, McBeth J. Is musculoskeletal pain more common now than 40 years ago?: Two population-based crosssectional studies. Rheumatology (Oxford). 2005;44(7):890-5.

42. Murphy LB, Cisternas MG, Pasta DJ, Helmick CG, Yelin EH. Medical expenditures and earnings losses among US adults with arthritis in 2013. Arthritis Care Res. 2018:70(6):869-76.

43. Battafarano DF, Ditmyer M, Bolster MB, Fitzgerald JD, Deal C, Bass AR, et al. 2015 American College of Rheumatology Workforce Study: supply and demand projections of adult rheumatology workforce, 2015-2030. Arthritis Care Res. 2018:70(4):617-26.

44. FitzGerald JD, Battistone M, Brown CR Jr, Cannella AC, Chakravarty E, Gelber AC, et al. Regional distribution of adult rheumatologists. Arthritis Rheum. 2013:65(12):3017-25.

\section{Publisher's Note}

Springer Nature remains neutral with regard to jurisdictional claims in published maps and institutional affiliations. 